\title{
PHYSICAL AND CHEMICAL INTERACTION OF ALUMINUM WITH TITANIUM AND NICKEL FOR FURTHER USE IN PARTS OF AGRICULTURAL MACHINERY
}

\author{
Ardak Dostayeva, Ainagul Toleuova \\ Karaganda Technical University, Kazakhstan \\ ardak_erkekyz@mail.ru,rymkul.ainagul@mail.ru
}

\begin{abstract}
Aluminum-titanium alloys are widely used as structural materials due to their high thermal conductivity, ductility, corrosion resistance, and ductility. Alloying these aluminum-titanium alloys with molybdenum and nickel provides a formation of strong and high-melting intermetallic compounds. That way the volume fractions of the strengthening phases are obtained in the alloys. The restoration of worn-out elements of the auxiliary parts which supply agricultural enterprises is considered as a reserve in increasing technical readiness. However, the technological processes used today to restore elements do not always meet the innovative, current requirements. In the work, the alloying elements selected are elements, such as molybdenum and nickel. An analytical review has shown that the binary systems Al-Ti, Al-Ni, Ni-Ti have been studied sufficiently. The data of the state diagrams of the ternary Al-Ti-Ni systems are not contained in the literature. The construction of phase diagrams of ternary systems will be carried out using the Thermo-Calc software. In this regard, the use of aluminum-titanium alloys in agricultural machinery increases their wear resistance by $2 \ldots 4$ times. The phase diagrams of the Al-Ti-Ni system are constructed using the Thermo-Calc program. Also, the polythermal sections of the Al-Ti-Ni system are constructed. It is found that a eutectic compound is formed between intermetallides. Intermetallic compounds $\mathrm{AlNi}_{3}$ and $\mathrm{AlTi}_{3}$ are in equilibrium with aluminum. The study of equilibrium state diagrams of Al-Ti-Ni ternary systems is an important theoretical basis for the creation of alloys with specified properties. The formation of intermetallic compounds is observed from the calculations of Thermo-Calc program.
\end{abstract}

Keywords: intermetallides, Al-Ti-Ni system alloy, phase diagram, wear resistance, corrosion resistance.

\section{Introduction}

Due to development of agricultural machinery from generation to generation, the design of engines becomes more complicated, operating temperatures increase and the weight of the engine itself decreases by the process of more constructive materials apply.

Binary alloys based on nickel and titanium [1-3] are generally known as materials that protect the machine part planes from wear or corrosion. In most cases, such alloys are preferably focused on providing the following properties: strength, wear resistance, heat resistance, reliable protection against corrosion, etc. The quality of coatings based on three-component $\mathrm{Al}-\mathrm{Ti}-\mathrm{Ni}$ alloys are not really studied, and therefore it is interesting to obtain an alloy, which is feasibly to have a combination of the mentioned physical, mechanical and chemical properties.

Thermodynamic evaluation of the combined aluminothermic reduction of titanium and nickel oxide was performed using the Thermo-Calc program. In order to solve a problem of modern material science, it is necessary to study the multicomponent phase equilibrium diagram, which can help using the Thermo-Calc program. The Thermo-Calc program allows to calculate the phase equilibrium state diagrams (liquidus and solidus plane projections), the phase number and composition, liquidus temperature, equilibrium and non-equilibrium solidus, phase formation under non-equilibrium conditions (calculated using the Sheil model). The program contains databases on alloys in terms of $\mathrm{Fe}$, $\mathrm{Ni}, \mathrm{Al}, \mathrm{Ti}, \mathrm{Mg}$, solders, slags, and more.

Thermo-Calc is a software package containing a large amount of thermodynamic data for performing calculations and constructing phase state diagrams. Calculations based on thermodynamic databases are performed by mean of expert assessment of experimental data with use CALPHAD method.

\section{Materials and methods}

An experimental testing of thermodynamic calculations is carried out on a laboratory Tamman' furnace (Figure 1). The charges were used during the experiments in order to form a low-melting slag system and accordingly to provide fission of the products formed near metallothermic renewal to titanium and nickel oxides, not counting aluminum. About 150-250 g of the charge was loaded into a graphite crucible, then kept for $15-20$ minutes at temperatures of $1550-1650{ }^{\circ} \mathrm{C}$, and subsequently along 
with the crucible it was taken from the furnace and cooled down in the air. Then X-ray phase and chemical analyses were performed.

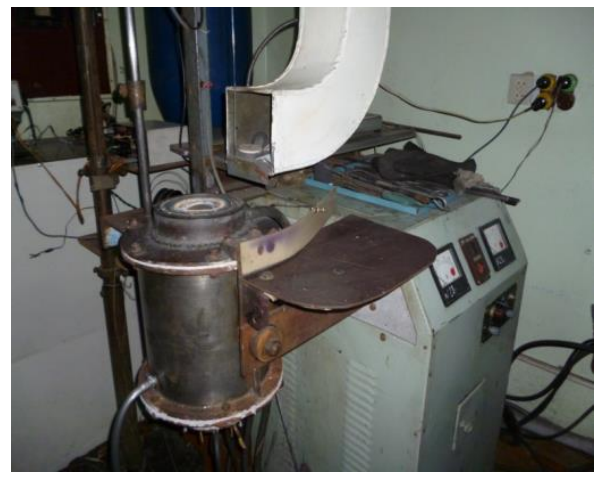

Fig. 1. Tamman' furnace

The X-ray phase analysis of the products was performed on an EMPYREAN X-ray diffractometer with automatic software control. The sample shooting was taken in filtered monochromatized $\mathrm{CuK \alpha}$ radiation. The diffractograms were decoded with database use of JCPDS and ASTM.

In order to reduce nickel and titanium oxides, so the thermodynamic calculations were made within the temperature range of $100-1700{ }^{\circ} \mathrm{C}$ and the pressure for them was $1 \mathrm{~atm}$. Aluminum was changing in the range from 0 to $50 \%$ wt. The temperature practically did not affect the nature of the reduction of elements. Because of this, the reaction of $\mathrm{TiO}_{2}+\mathrm{Ni}_{2} \mathrm{O}_{3}$, the aluminum consumption effect on the ingredients distribution between alloy and slag was studied at the optimal temperature of $1580{ }^{\circ} \mathrm{C}$ in accordance with a viscosity and a melting point.

The obtained calculations using Thermo-Calc included the following compounds: $\mathrm{Ni}_{3} \mathrm{Ti}, \mathrm{NiAl}$, $\mathrm{Ni}_{2} \mathrm{Al}_{3}, \mathrm{AlTi}, \mathrm{Al}_{3} \mathrm{Ti}, \mathrm{NiAl}_{3}$ which formed in the reaction of $\mathrm{TiO}_{2}+\mathrm{Ni}_{2} \mathrm{O}_{3}$ due to aluminum. Intermetallides consisting of three components have not been studied. Nickel of $90 \%$, and titanium of $80 \%$ were derived from the charge according to the calculations,.

During laboratory studies, the using charges contain $\mathrm{TiO}_{2}, \mathrm{Ni}_{2} \mathrm{O}_{3}, \mathrm{Al}$, due to which the intermetallic compounds $\mathrm{Ti}-\mathrm{Al}$ and $\mathrm{Al}-\mathrm{Ni}$ formed. Figure 2 shows the alloy and slag after melting. The chemical composition of the resulting alloy and slag is shown in Table 1.

Table 1

Chemical composition of the resulting alloy and slag Ti-Al-Ni

\begin{tabular}{|c|c|c|c|}
\hline Products & Ti & Al & Ni \\
\hline Alloy & 16.2 & 53.4 & 27.0 \\
\hline Slag & 1.5 & 38.0 & 2.49 \\
\hline
\end{tabular}

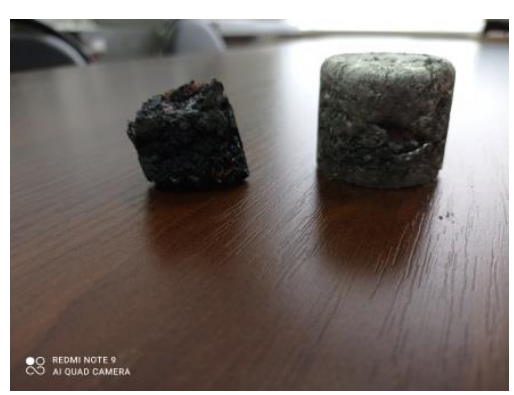

Fig. 2. Slag and metal pieces

Nickel and titanium were derived in slag, which indicated that these elements had been extracted at a high level in the alloy. The extraction in the alloy made up nickel of $93-99 \%$ and ttitanium of $80-90 \%$.

The X-ray phase analysis of the alloys showed that the alloy mainly contains the compound $\mathrm{Al}_{63.73} \mathrm{Ni}_{28} \mathrm{Ti}_{27.55}\left(\mathrm{Al}_{2.3} \mathrm{NiTi}\right)$, as well as a small number of compounds $\mathrm{Al}_{3} \mathrm{Ti}, \mathrm{Al}_{3} \mathrm{Ni}$ and $\mathrm{Al}_{3} \mathrm{Ni}_{2}$.

The microhardness value reached 700-1000 HV, which is 5-7 times higher than the steel material. 


\section{Results and discussion}

The novelty of the article is that for the first time isothermal and polythermal sections of the Al-NiTi system were built using the Thermo-Calc program. The isothermal and polythermal sections of the Al-Ni-Ti system were constructed using the Thermo-Calc program. Figure 3 shows the isothermal cross section of the Al-Ni-Ti system at $600{ }^{\circ} \mathrm{C}$.

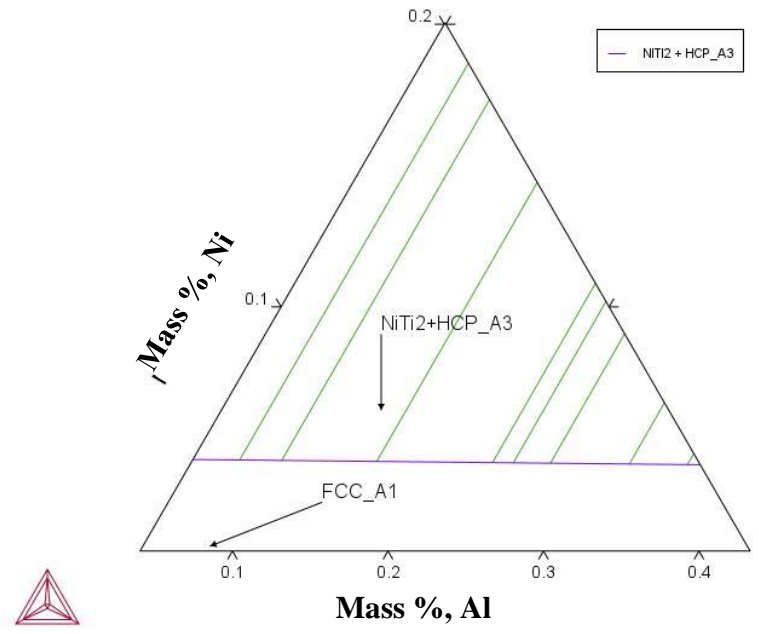

Fig. 3. Isothermal cross section of Al-Ni-Ti system at $600^{\circ} \mathrm{C}$

The program determined that $\mathrm{NiTi}_{2}$ and solid solutions are formed in the isothermal section. That is, the intermetallic compounds observed in our alloys upon melting have been fundamentally proven.

The following intermetallic compounds were formed in the alloys of the Al-Ni-Ti system: $\mathrm{Al}_{3} \mathrm{Ti}$, $\mathrm{Al}_{2} \mathrm{Ti}, \mathrm{AlTi}, \mathrm{AlTi}_{3}, \mathrm{Al}_{3} \mathrm{Ni}_{5}, \mathrm{Al}_{3} \mathrm{Ni}, \mathrm{AlNi}_{3}, \mathrm{AlNi}, \mathrm{Ti}_{2} \mathrm{Ni}, \mathrm{TiNi}, \mathrm{TiNi}_{2}, \mathrm{TiNi}_{3}$.

Figure 4 shows an X-ray image of the intermetallic phase of nickel observed on the surface of aluminum. In other words, the presence of intermetallic compounds in the molten alloy, the isothermal section, was clearly seen on the X-ray diffraction pattern. Our computational study was consistent with the experimental study.

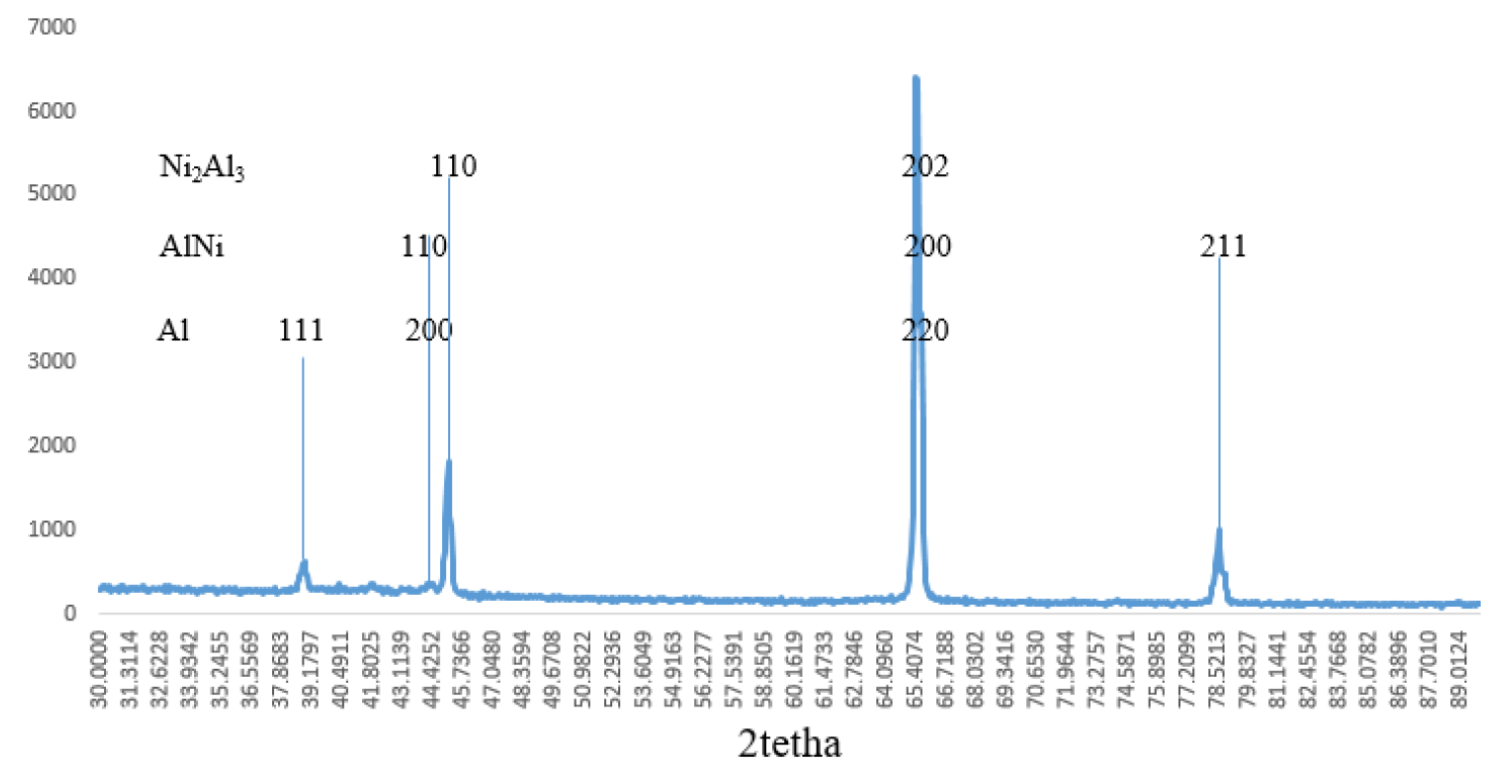

Fig. 4. Diffraction pattern of nickel on the surface of aluminium system Al-Ni-Ti

In the $\mathrm{Al}-\mathrm{Ni}-\mathrm{Ti}$ system, the three-component compound $\mathrm{AlNi}_{2} \mathrm{Ti}$ similar to the structural type $\mathrm{AlCu}_{2} \mathrm{Mn}$ was detected by firing at $600{ }^{\circ} \mathrm{C}$, the formation of which was also observed at $800{ }^{\circ} \mathrm{C}$ [4]. The dependence of the grid parameters on the results obtained using the Thermo-Calc program is established (Figure 5). It is known that the atomic radii of aluminum and titanium are close in size [5]; therefore, 
the period of the three-component phase lattice does not change significantly upon replacement, as evidenced by the graph in Figure 3.

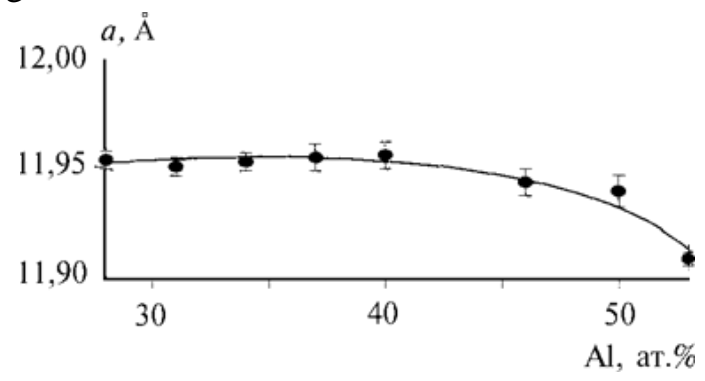

Fig. 5. Dependence of lattice parameters of the intermetallic compound $\mathrm{Al}_{3} \mathrm{NiTi}$

Due to the lack of information in the references about the cross sections of the equilibrium state diagram of the Al-Ni-Ti system, polythermal sections were constructed using the Thermo-Calc program (Figure 6).

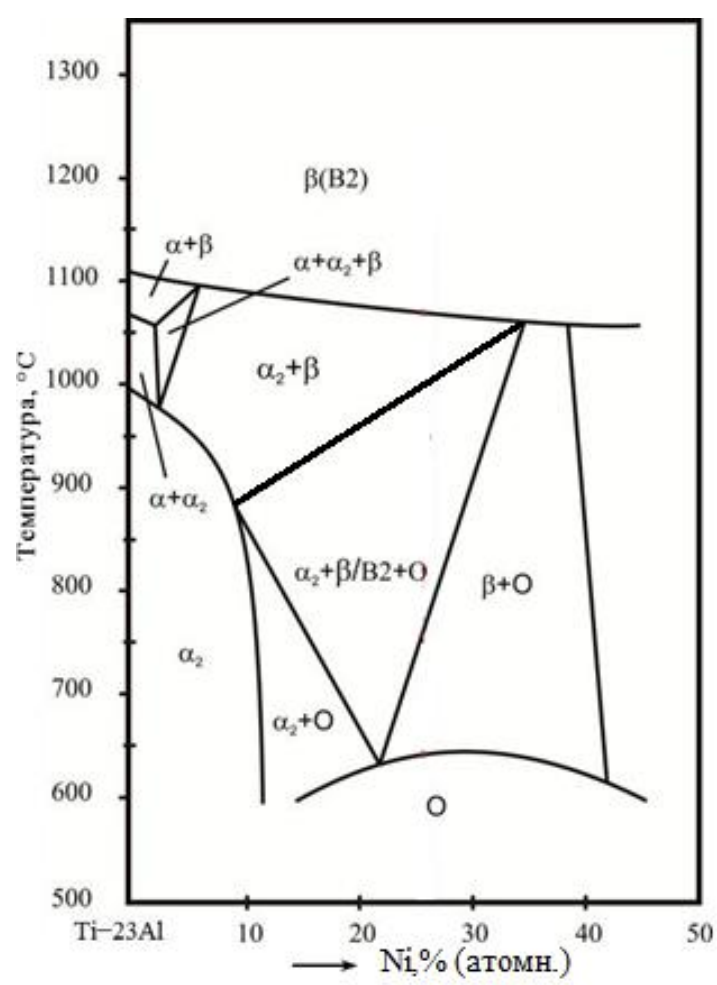

Fig. 6. Polythermal section of $\mathrm{Al}_{2,3} \mathrm{NiTi}$ (\%(atom.)) of $\mathrm{Al}-\mathrm{Ni}$-Ti system

The microstructure of this alloy in the as-cast state is observed in the grains of the $\beta$-phase with the dispersion of $\alpha$ and $\alpha_{2}$, the phases of the polythermal section are also clearly visible in X-ray diffraction analysis.

Hardness was measured using a Vickers hardness tester. The results are shown in Table 3.

Table 3

Results of hardness of alloy of Al - Ni - Ti system

\begin{tabular}{|c|c|}
\hline Alloy & $\begin{array}{c}\text { Average value of hardness, HV, } \\
\text { MPa }\end{array}$ \\
\hline 1 & 9700 \\
\hline 2 & $\mathbf{9 8 0 0}$ \\
\hline 3 & 9650 \\
\hline 4 & 9780 \\
\hline 5 & 9720 \\
\hline
\end{tabular}




\section{Conclusions}

The higher the titanium content, the higher the hardness of the alloy. As it can be seen from the isothermal and polythermal sections, the more intermetallic phases, the higher the properties of the alloy. Thus, the results of the studies performed show that alloys of the Al-Ni-Ti system are widely used in various industries (mechanical engineering, metallurgy, agriculture) as a heat-resistant solid material.

The presence of the intermetallide $\mathrm{Al}_{2,3} \mathrm{NiTi}$ in the $\mathrm{Al}-\mathrm{Ti}$ - $\mathrm{Ni}$ alloy was studied during the reduction of nickel and titanium oxides together with aluminum.

The higher titanium content leads to better hardness of the alloy. As it can be seen from the isothermal and polythermal sections, more intermetallic phases have higher properties of the alloy. Thus, the results of the conducted studies show that the alloys of the Al-Ni-Ti system are widely used in various industries (mechanical engineering, metallurgy, agriculture) as a heat-resistant solid material.

\section{References}

[1] Kothari K., Radhakrishnan R., Wereley N.M. Advances in Gamma Titanium Aluminides and Their Manufacturing Techniques // Progress in Aerospace Sciences, 2012, Vol. 55, P. 1-16. DOI: 10.1016/j.paerosci.2012.04.001

[2] Kablov E.N. et al., Study of the structure and properties of heat-resistant alloys based on titanium aluminides with microadditions of gadolinium, Materialovedenie. 2017, No. 3, pp.3-10.

[3] Dostaeva A.M., Isagulov A.Z., Ibatov M.K., Toleuova A.R., Naboko E.P. Al-Ti baza қorytpalarynyn kyrylymdyk fazalyk kuiine microkospalardyn aserin zertteu // Proceedings of the University -2021 - №1 (82), pp. 20-25, DOI: 10.52209/1609-1825_2021_1_20

[4] Smagulov D.U., Belov N.A., Dostayeva A.M. Roasting effect on the electrical resistivity of the Al$0.5 \% \mathrm{Zr}$ alloys // Bulletin of the university of Karaganda-Physics - 2015, No. 4, pp.19-23.

[5] Kolachev B.A., Elagin V.I., Livanov V.A. Metallurgy and heat treatment of non-ferrous metals and alloys. 4th ed. Moscow: MISiS, 2005.432 p. 